\title{
Treatment of Myopia - Current Status and Recent Advances
}

\author{
An Expert Interview with Andrzej Grzybowski \\ Department of Ophthalmology, Poznań City Hospital, Poland; Department of Ophthalmology, University of Warmia and Mazury, \\ Olsztyn, Poland
}

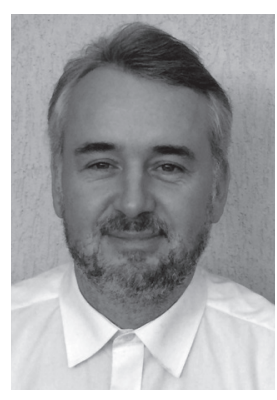

\begin{abstract}
Andrzej Grzybowski
Andrzej Grzybowski is Professor of Ophthalmology and Chair of Department of Ophthalmology, University of Warmia and Mazury, Olsztyn, Poland and Head of Institute for Research in Ophthalmology, Foundation for Ophthalmology Development, Poznan, Poland. He is active in international scientific societies including EURETINA (Co-opted Board member), the American Academy of Ophthalmology (AAO; International Fellow; member of the Global ONE Advisory Board and Museum of Vision's Program Committee), the International Society of Bilateral Cataract Surgeons, the International Council of Ophthalmology (programme coordinator for the World Council of Optometry from 2011 to 2018), Cogan Society, the European Association for Vision and Eye Research (EVER), the European Society of Cataract and Refractive Surgeons (ESCRS) (Curator of ESCRS Archive), and representative of Poland at the International Society of Refractive Surgery International Council. He became a lifelong member (chair LIV) of the European Academy of Ophthalmology) and its Treasurer. He has organised sessions on myopia at major international ophthalmic meetingS, EVER 2014, AAO 2016 and 2017, EURETINA 2017 and the World Congress of Paediatric Ophthalmology and Strabismus 2017. Andrzej Grzybowski is on the Editorial Board of several international medical, ophthalmic and historical journals, including Acta Ophthalmologica, Graefes' Archive for Experimental and Clinical Ophthalmology, Translational Vision Science and Technology and Neuro-Ophthalmology. He has been an active editor, editor-in-chief and author of more
\end{abstract} than 350 peer-reviewed international publications (total impact factor higher than 700), and a reviewer for more than 20 journals.

\section{Keywords}

Myopia, atropine, pirenzepine, fluid misdirection syndrome, EURETINA

Disclosure: Andrzej Grzybowski has nothing to declare in relation to this article. This is an expert interview and as such has not undergone the journal's standard peer review process.

Authorship: All named authors meet the International Committee of Medical Journal Editors (ICMJE) criteria for authorship of this manuscript, take responsibility for the integrity of the work as a whole, and have given final approval to the version to be published.

Open Access: This article is published under the

Creative Commons Attribution Noncommercial License, which permits any non-commercial use, distribution, adaptation and reproduction provided the original author(s) and source are given appropriate credit.

Received: 24 November 2017

Published Online: 22 December 2017

Citation: European Ophthalmic Review, 2017;11(2):85-6

Corresponding Author: Andrzej Grzybowski,

Department of Ophthalmology, Poznań City Hospital

3 Szwajcarska St, 361-285 Poznań, Poland.

E: ae.grzybowski@gmail.com

Support: No funding was received in the publication of this article.
T he incidence of myopia is increasing and represents a major global economic and social burden. ${ }^{1}$ In addition to its disadvantages in terms of vision, myopia increases the risk of myopic macular degeneration, retinal detachment, glaucoma and cataract and is a leading cause of visual impairment and blindness worldwide. ${ }^{2}$ Pharmacological, environmental and optical interventions have been used to try to slow the progress of myopia. While spectacles and contact lenses have a long history in controlling accommodative responses, they do not slow progression. In an expert interview conducted at EURETINA 2017, Andrzej Grzybowski of the Institute for Research in Ophthalmology, Poznan, Poland discusses the current status of myopia and its treatment, as well as discussing new technologies aimed at delaying progression of the condition.

\section{Q: Why has the prevalence of myopia increased so much in recent years?}

The modern rise in myopia mirrors a trend for children in many countries spending more time engaged in reading, studying or glued to computers and smartphone screens. The evidence suggests that these environmental factors changes play a significant role, particularly in East and Southeast Asia. In some places, children cannot get enough outdoor light: there are too few hours of daylight, the sun is too fierce or the cold too intense..$^{3.4}$

\section{Q: What have been the most important advances in non-surgical treatment for myopia in the last year?}

High-dose atropine ( $1 \%$ and $0.5 \%$, moderate-dose atropine $(0.1 \%$ and low-dose atropine $(0.01 \%)$

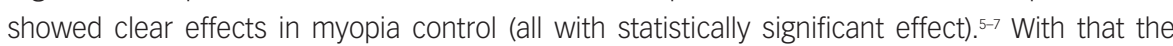
preliminary results of ongoing studies regarding the efficacy of pirenzepine, increased light exposure (e.g., using the Kurango study lamp) and 7-methylxantine are promising. ${ }^{.}$

\section{Q: What are the benefits and limitations of the use of atropine eye drops for the treatment of myopia?}

High-dose atropine was proved to be superior to other interventions. The side-effects might include temporary stinging, blurred vision, pupil dilation and eye irritation, limiting a long-term application. ${ }^{9}$ This leaves low-dose atropine, pirenzepine and soft contact lenses with myopia control features 
(for example, peripheral defocus modifying designs) as viable options for the active management of myopia progression. ${ }^{10-12}$

\section{Q: What is your opinion on the use of toric orthokeratology for the treatment of myopia?}

The use of orthokeratology is limited by its complexity and cost. However, this treatment showed moderate effects for myopia control in several studies. ${ }^{13,14}$

\section{Q: Which presentations would you highlight from this year's EURETINA meeting?}

My highlight was the presentation regarding the fluid misdirection syndrome. In a recent review article we proposed a unified definition of this syndrome, known for almost 150 years as malignant glaucoma. ${ }^{15}$ It might occur intraoperatively, however very few papers have been published on the topic. Anecdotally, most anterior segment surgeons report to have experienced such cases. $\square$
1. Holden B, Sankaridurg P, Smith E, et al., Myopia, an underrated global challenge to vision: where the current data takes us on myopia control, Eye (Lond), 2014;28:142-6.

2. Holden BA, Fricke TR, Wilson DA, et al., Global prevalence of myopia and high myopia and temporal trends from 2000 through 2050, Ophthalmology, 2016;123:1036-42.

3. French AN, Morgan IG, Mitchell P, et al., Risk factors for incident myopia in australian schoolchildren: the sydney adolescent vascular and eye study, Ophthalmology, 2013;120:2100-8.

4. Grzybowski A, Armesto A, Szwajkowska M, et al., The Role of Atropine Eye Drops in Myopia Control, Curr Pharm Des, 2015;21:4718-30.

5. Chia A, Chua WH, Cheung YB, et al., Atropine for the treatment of childhood myopia: safety and efficacy of 0,5\%, 0,1\% and $0,01 \%$ Doses (Atropine for the Treatment of Myopia 2),
Ophthalmology 2012:119:47-354

6. Chia A, Chua WH, Wen L, et al., Atropine for the treatment of childhood myopia: changes after stopping atropine $0.01 \%, 0.1 \%$ and 0.5\%, Am J Ophthalmol, 2014;157:451-7.

7. Chia A, Li W, Tan D, et al., Full- field ectroretinogram findings in children in the atropine treatment for myopia (ATOM 2) study, Doc Ophthalmol, 2013;126:177-86.

8. Trier K, Munk Ribel-Madsen S, Cui D, Brøgger Christensen S, Systemic 7-methylxanthine in retarding axial eye growth and myopia progression: a 36-month pilot study, J Ocul Biol Dis Infor, 2008;1:85-93.

9. Huang J, Wen D, Wang Q, et al., Efficacy comparison of 16 interventions for myopia control in children: A network metaanalysis, Ophthalmology, 2016:123:697-708.

10. Smith EL 3rd, Prentice Award Lecture 2010: A case for peripheral optical treatment strategies for myopia, Optom Vis Sci, 2011; 88:1029-44.
11. Smith EL 3rd, Campbell MC, Irving E, Does peripheral retinal input explain the promising myopia control effects of cornea reshaping therapy (CRT or ortho-K) \& multifocal soft contact lenses?, Ophthalmic Physiol Opt, 2013;33:379-84.

12. Charman WN, Radhakrishnan $\mathrm{H}$, Peripheral refraction and the development of refractive error: a review, Ophthalmic Physiol Opt, 2010;30:321-38.

13. Cho P, Cheung SW, Retardation of myopia in Orthokeratology (ROMIO) study: a 2-year randomized clinical trial, Invest Ophthalmol Vis Sci, 2012;53:7077-85.

14. Lee YC, Wang JH, Chiu CJ, Effect of orthokeratology on myopia progression: twelve-year results of a retrospective cohort study, BMC Ophthalmol, 2017:17:243.

15. Grzybowski A, Kanclerz P. Acute and chronic fluid misdirection syndrome: pathophysiology and treatment, Graefes Arch Clin syndrome: pathophysiology and treatment, Graefes Arch Cin s00417-017-3837-00). 